\title{
LÁZARO DE TORMES O EL OFICIO DE SERVIR
}

Desde sus primeros pasos, como mozo de ciego, hasta el final, como pregonero real y, de paso, del arcipreste, vemos a Lázaro de Tormes en un vertiginoso aprendizaje del oficio de criado, que culmina en la maestría del buen servidor. Como todo principiante, Lázaro debe pasar por duras pruebas y variadas enseñanzas con cada uno de sus sucesivos amos antes de llegar a dominar su oficio, pero, a diferencia de otros niños y muchachos dedicados a aprender tareas productivas, las repetidas durezas cotidianas no lo llevan al ejercicio de labores útiles, sino al arte del vivir parasitario. En este sentido, Lazarillo es el "anti-aprendiz" a quien cada amo da una lección imborrable de ocio, picardía y engaño. En la peculiar visión que esta Vida nos presenta de las fortunas y adversidades del personaje-narrador ${ }^{2}$, para quien servir es un negocio basado en el ocio, el aprendiz de criado se nos muestra como la antítesis del hombre productivo.

Las lecciones que el mozo recibe de sus diversos amos son graduales. El primero, el ciego, lo adiestró con trampas y malos tra-

${ }^{1}$ Cito por la última edición del Lazarillo de Tormes, ed. Francisco Rico, con un apénd. bibl. de Bienvenido C. Morros, Cátedra, Madrid, 1987 (Col. Letras Hispánicas, 44). En el texto, entre corchetes, indico el núm. del tratado y la página. La bibliografía de B. C. Morros, que abarca hasta 1987, es la más completa que conozco. A ella remito a los lectores, ya que no es mi intención citar todas las obras consultadas para este estudio.

${ }^{2}$ Sobre la técnica narrativa en la obra, remito a los trabajos de MARGIT FRENK, esp. "Lazarillo de Tormes: autor-narrador-personaje", HHM-80, pp.185-192. La autora señala los sucesivos niveles de Lázaro como autor, narrador y personaje; por mi parte, en ciertos momentos percibo también niveles simultáneos de estas funciones, en cuyo caso utilizo estos sustantivos en aposición. 
tos en la dura "carrera de vivir", advirtiéndole la necesidad de saber más que el diablo. Con el clérigo supo sobrevivir poniendo en práctica enseñanzas y astucias desarrolladas a fuerza de desfallecer de hambre. El aprendizaje de Lázaro con estos dos primeros amos fue iniciación en un oficio despojado de toda ternura, y la relación del criado con sus maestros se sustentó en la sujeción y el desafecto.

No puede sorprendernos que ambos personajes aparezcan siempre caracterizados por nombres y epítetos cuya carga emotiva es unívoca. Así, el ciego casi siempre es recordado a lo largo de los tres primeros tratados como avariento, mezquino, malo, traidor, cruel, pecador, maldito, perverso. A su vez, el clérigo de Maqueda no sólo es calificado en estos mismos términos sino, además, con otros como cuitado, malaventurado, ruin, lacerado, mísero, trasgo, brujo, desventurado. Sin embargo, importa recordar que entre el primero y el segundo amo hay una diferencia significativa: mientras que a veces Lázaro expresa sentimientos encontrados hacia el ciego, esto jamás sucede con el clérigo, pues " "era el ciego para con éste un Alejandro Magno, con ser la mesma avaricia", [II, p. 47].

Es más, el personaje-narrador que desde niño fue colocado por su madre como guía de ciego, "con buen amo", recuerda que éste prometió recibirlo "no por mozo sino por hijo", evocando así la fórmula tradicional de los contratos de aprendiz. Al mismo tiempo, en esta referencia hay un indudable propósito de desenmascarar los abusos que, tanto en la narración como en la sociedad de la época, los amos cometen contra sus pupilos amparados por estas fórmulas paternalistas. A pesar de la intención irónica, no cabe duda que en la obra hay un cierto reconocimiento hacia el ciego que jamás surge por el clérigo. Lázaro a menudo agradecerá las enseñanzas recibidas del ciego, aunque fueran inculcadas con sangre, y recordará a su primer amo como un maestro e, incluso, un padre capaz de apiadarse de él aun en medio de la crueldad: “'después de Dios éste me dio la vida'” [I, p. 24]. Más de una vez se refiere al "bueno" de su primer amo no sin cierta admiración y lo califica de astuto, sagaz, "un águila" en su oficio [I, p. 14], de "gran maestro"' [III, p. 87] que le enseñó "mil cosas buenas" [I, p. 46]. En otros momentos, no falta en Lázaro un dejo de lástima por la miseria y el dolor del desgraciado ciego cuando lo evoca pobre, triste, desesperado.

Muy otros son los sentimientos hacia el segundo amo. Al "cruel sacerdote" que encarna "toda la laceria del mundo" [II, p. 47], 
el niño sólo le debe terribles hambres y descalabros crueles. La relación con el clérigo carece de toda deuda de aprendizaje y está definida únicamente por el desafecto del mísero mozo por el amo ruin y mezquino: nada le importa al clérigo la suerte de su criado y poco tiene éste que agradecerle a aquél sino el hambre y los malos tratos.

Los vaivenes de Lázaro niño y muchacho en este aprender a servir culminan en la elaborada y compleja relación con su tercer amo. El mozo, apenas adolescente, y el todavía joven escudero se acercan en una singular convivencia que marcará hondamente el futuro de nuestro protagonista. Si el punto de partida es, una vez más, la necesidad de servir a un amo necesitado de criado, este tercer aprendizaje se distingue radicalmente de los anteriores por la total ausencia de violencia entre amo y criado, por el vínculo afectivo y la comunicación que se desarrolla entre ambos, por la ausencia de falsos paternalismos, por la inversión de papeles que lleva al sirviente a socorrer al hambriento señor, por la paciencia con que éste le explica y enseña al humilde Lázaro los valores de un estamento privilegiado. Además, el encuentro con el escudero sirve al autor para que el personaje-aprendiz transite por los tres estamentos de la sociedad y los observe desde tres miras, con la inocencia del niño y el mozuelo, pero, también, con la perspicacia irónica del maduro narrador-personaje-autor de esta singular memoria epistolar.

En el recorrido por los distintos estamentos de este Lázaro tantas veces resucitado de hambres y descalabros, destaca la peculiar selección que el autor hace de los tres principales representantes de cada estado. Cada uno de estos tres tipos se convierte, en realidad, en la representación y en el paradigma del segmento más bajo de su clase, en la escoria de su estamento: el mísero ciego villano, el clérigo vil, el escudero famélico y degradado.

La elección de estos tres personajes es una peculiaridad narrativa que nos obliga a reflexionar sobre esta representación tan especial de la sociedad: los tres primeros amos son seres marginados que en el ir y venir del personaje-narrador se convierten en tres arquetipos sociales. Otros más aparecen al comienzo de la obra, o se sucederán luego como representantes del estado llano y del clero, pero todos reiteran un mismo patrón como tipos desposeídos y marginados.

También llama la atención la simpatía que el narrador-autor transmite por los miembros de los dos estados laicos frente al indudable rechazo del eclesiástico. Esto no sólo es cierto de los ac- 
tores principales, sino de todos los personajes de la obra. Los primeros - el molinero ladrón, la madre prostituida, el moro esclavo- se nos aparecen como tres tristes víctimas de la miseria y el hambre. Los que surgen a partir del cuarto tratado, en particular los relacionados con la iglesia, son representados - como el clérigo de Maqueda antes- en toda su bribonería e impudicia: el fraile, el buldero, el capellán y el arcipreste. Sólo Lázaro y el escudero destacan como dos tipos sin par en su género. El primero, en su papel de memorioso pero selectivo observadornarrador que, por su excepcional movilidad, recorre a través de su vida toda la amplia gama social de la marginación y la describe; el segundo, como único ejemplar del estado nobiliario, aunque sea en su nivel más bajo e, incluso, degradado por la pobreza. La relación excepcional que se entabla entre este tercer amo y Lázaro nos parece un hito en la obra y un parteaguas indiscutible entre el pasado y el futuro de la vida del criado.

\section{El ESCUDERO Y SU MOZO}

El tercer tratado se distingue de los anteriores, ante todo, desde un punto de vista formal. Para empezar, es el más extenso de la obra, ya que ocupa casi su tercera parte y supera en poco menos del veinticinco por ciento al primero, que le sigue en extensión. También es distinto en lo que se refiere al cambio en el modo de comunicación de Lázaro con sus amos, pues adopta la forma dialogística o la discursiva a diferencia de los dos tratados que lo preceden. Mientras los primeros son, ante todo, narrativos, en el tercer tratado abundan los diálogos entre el escudero y su mozo; además, a éstos se suma un largo monólogo del hidalgo y repetidas reflexiones, soliloquios o apartes casi teatrales del criado-narrador. Lo anterior contrasta claramente con el resto de la obra, donde los escasísimos y breves diálogos del primero y del último tratado quedan dominados por la narración del personaje-autor.

En lo que concierne al lenguaje, hay un marcado contraste entre este tratado y los dos anteriores. En las raras ocasiones previas en que Lázaro dialoga con otros personajes, su habla es popular y responde a la norma del estado llano. En tres ocasiones llama "tío" al ciego, lo cual se repite cuando, en el segundo tratado, se dirige al calderero; en sus escasísimos diálogos con el clérigo nunca aparece una fórmula para dirigirse a él. Sólo en un par de ocasiones, cerca del final de esta segunda narración, cuan- 
do se refiere al de Maqueda como "el señor mi amo" [II, pp. $63,70]$, se presenta un cambio hacia una forma más culta y, tal vez, más aristocratizante, como si el anónimo autor, a la vez narrador adulto, olvidara la norma previa de su protagonista mozuelo.

En el tratado tercero el contraste en el lenguaje es notable. En las pocas horas que transcurren desde la mañana, cuando a la pregunta de si busca amo Lázaro le responde al escudero: "Sí señor", hasta las dos de la tarde, cuando éste le pregunta si ha comido y aquél responde: "No, señor, [...] Vuestra Merced" [III, p. 76], el muchacho cambia su habla popular por la de un comedido criado de noble. No importa que hasta entonces sus casi trece primeros años de vida hayan transcurrido entre los sectores sociales más marginados ni que antes de encontrar al tercer amo fuera tildado por todos de "bellaco y gallofero"; en las seis horas que siguen a su encuentro con el hidalgo ${ }^{3}$, Lazarillo se transforma en educado y discreto servidor, capaz de mentir y callar todo lo que le parecía "no ser para en cámara" [III, p. 75]. Es imposible creer que en tan poco tiempo el mozo haya aprendido tan bien el lenguaje y los modales cortesanos. En cambio, resulta lógico que al recordar su vida, al cabo de la cual ha aprendido a emular el vivir ajeno, el personaje-narrador ya maduro haga suyas las fórmulas retóricas de un estamento dominante que admira con la infranqueable distancia social de su clase. Este mimetismo es aún más verosímil si tenemos en cuenta que el escudero

${ }^{3}$ Es notable el contraste de este tratado con el resto de la obra (e, incluso, con la literatura española de la época) en lo que se refiere a la minuciosa precisión con que se señala el paso del tiempo. Desde el primer párrafo se marca con puntillosa exactitud el sucederse de las horas. El reloj tiene aquí una excepcional función dramática: es como un coro que con sus campanadas puntúa rítmicamente el hambre manifiesta de Lázaro y la más recatada de su pobre amo. Frente al tiempo "natural", agrícola, del pastoreo y de la pesca y al tiempo "espiritual", medido por las oraciones eclesiásticas, en los albores del capitalismo, sabemos que el reloj introdujo una regulación mecánica de las actividades sociales productivas. Sin embargo, en el Lazarillo, las campanadas del reloj se suceden para medir las horas y los días de ocio y hambre del mozo y su amo, así como ese tiempo tan individual y subjetivo, tan aparentemente moderno, de la soledad y la angustia. El lector curioso puede consultar dos sugerentes estudios: E. P. THOMPSON, "Tiempo, disciplina de trabajo y capitalismo industrial", en Tradición, revuelta y consciencia de clase, CríticaGrijalbo, Barcelona, 1979, pp. 239-293 y DAvid S. LANDEs, Revolution in time: clocks and the making of the modern world, Harvard University Press, Cambridge, MA, 1983. 
es el único amo que no sólo lo trata sin dureza sino que entabla con él una comunicación humana, el único a quien Lázaro "quería bien" y el único por quien el mozo siente que es justo "de haber mancilla", es decir, compasión y piedad [III, p. 92].

Es más, si estas transformaciones en el habla, desde un punto de vista social y lingüístico parecen improbables en tan breves horas, en cambio, son coherentes con la intención literaria del autor de hacer de este tratado un hito en la formación del personaje y en su aprendizaje de buen servidor. Al entablarse la relación con el escudero, Lázaro deja de ser mozo de ciego y de clérigo miserables, para convertirse en discípulo del escuderil hidalgo. Es evidente que el muchacho nunca podrá ingresar al estamento noble, pero nada le prohíbe observar e imitar sus formas y modos.

Este tercer amo y maestro es para Lázaro ruptura con el pasado y apertura hacia el futuro. De él - sin duda, el más afable y desvalido de sus amos-, Lázaro recibe enseñanzas indelebles, ya que es el propio escudero quien lo introduce a los principios mismos del arte de servir ${ }^{4}$. En efecto, este miembro arruinado de una pequeña nobleza degradada - antes guerrera y ahora laca$\mathrm{ya}^{5}$-, sólo aspira, a su vez, a encontrar un amo más encumbrado a cuyo servicio entrar: "ún señor de título" del cual ser "muy gran su privado" [III, p. 104].

Lázaro recibe del escudero algunas de las lecciones más perdurables: no como aquellas enseñadas con sangre por sus anteriores amos, sino las dadas con la suavidad del lenguaje y los modos cortesanos. Si el ciego lo "alumbró e adestró en la carrera de vivir" [I, p. 24], gracias al escudero el mozo se instruye en la importancia de las apariencias en el vestir y el andar, en la necesidad de saber elegir amos que lo ayuden a ascender en la vida, en aprender a complacerlos y adularlos, en dejar de lado principios y virtudes. A través de las palabras del propio hidalgo, el sirviente aprende que lo que más cuenta para prosperar es tener

${ }^{4}$ Las diferencias entre "trabajo" y "servicio" las examina José ANtoNio Maravall, "Relaciones de dependencia e integración social. Criados, graciosos y pícaros", $I \& L, 4$ (1977), 3-32. Aunque el autor no trata directamente el Lazarillo, los temas que toca iluminan también esta obra en un contexto que aquí me interesa. La interpretación dialéctica que propone MAURICE Molho de la relación del amo noble con el pícaro como esclavo es también sugerente, aunque tangencial aquí: "Picarisme des origines ou la dialectique du maitre et de l'esclave', Caliban, Toulouse, 1983, 5-17. (Agradezco al autor su amabilidad al enviarme este artículo).

${ }^{5}$ Antonio Domínguez Ortiz, Las clases privilegiadas en la España del Antiguo Régimen, Istmo, Madrid, 1973, pp. 56-57. 
muchas galas de esta calidad que hoy día se usan en palacio y a los señores dél parecen bien, y no quieren ver en sus casas hombres virtuosos, antes los aborrescen y tienen en poco y llaman nescios y que no son personas de negocios ni con quien el señor se puede descuidar.

En síntesis, un Lázaro todavía libre de tales malicias recoge en los pícaros consejos del escudero la necesidad de ser el privado astuto y discreto que se arrima a buen amo para labrarse un lugar protegido y seguro a cambio de "servir y contentar" [III, pp. 104-106].

Por primera vez en su vida, el muchacho marginado encuentra quien le enseñe a avanzar en la vida no a golpes sino con amables consejos de buen maestro. Lázaro, aprendiz de valido, recoge en estas apicaradas lecciones cortesanas los fundamentos que, en su vida futura, pondrá en exitosa práctica al servicio del arcipreste.

\section{Apariencia y engaño: hacia el triunfo de Lázaro}

La aparición en el relato de este noble pobretón y marginado marca una inversión de las normas que, en adelante, caracterizará la relación de Lázaro con el mundo. Una tras otra se suceden las vueltas y reveses: se invierten los papeles y el criado mantiene al amo; se invierten los valores y el hidalgo instruye al plebeyo en las picardías de servir y agradar; se invierten las tradiciones y es el señor el que abandona al sirviente. Bien lo sintetiza Lazarillo cuando reflexiona que "hacía mis negocios tan al revés, que los amos, que suelen ser dejados de los mozos, en mí no fuese ansí, mas que mi amo me dejase y huyese de mí" [III, p. 110].

En la base de esta trasposición de las normas están el engaño y la apariencia que trastocan la realidad y que, en adelante, son constantes de la vida del personaje. Lázaro González Pérez acaba por renunciar a sus verdaderos pero comunes apellidos y adopta con irrisorio orgullo el apodo que refleja su pobre nacimiento en el Tormes. Por arte de birlibirloque, el hijo de molinero ladrón y de madre amancebada con negro esclavo asume un nombre que, por sí solo, podría alcanzar engañosas pretensiones de linaje honorable si no fuera que también evoca indudable burla de nombres heroicos. ¿Acaso el lector no percibe en este pícaro del río, casi podríamos decir del arroyo, que toma para sí el sonoro ape- 
lativo Lázaro de Tormes" ${ }^{6}$ una referencia paródica al "doncel del mar" que acabó llamándose Amadís de Gaula? Por otra parte, cabría preguntar si esta voluntad de satíricas resonancias caballerescas no anticipa por más de medio siglo la intención similar de aquel gran parodista de Amadís, quien también elige su propio nombre y proclama que "mi linaje soy yo". ¿Será casual que al tomar como patronímico el nombre del río donde, por accidente, Lázaro vio la luz, él también se convierta en creador de su propio linaje o hay aquí una intención, velada por la risa, de criticar la creciente obsesión castellana por las probanzas de limpieza de sangre y el correspondiente auge de fabricadas genealogías? ¿Frente a la hegemonía de los títulos nobiliarios será ésta una artimaña plebeya para ascender en una sociedad rígidamente estamental? Sean cuales sean los motivos para la elección del nombre, lo cierto es que desde el comienzo de la Vida hay todo un mundo de engaños que subvierten la realidad y arrajan al lector a un torbellino de ambigüedad y apariencia constantes.

Si engañoso es el nombre del de Tormes, también lo es el hábito. Después de los primeros tratados, en los que se dibuja un Lazarillo harapiento, descalzo y desdentado de por vida [I, p. 33], pasamos al Lázaro adolescente que, gracias al escandaloso mercedario, calza sus primeros zapatos [IV, p. 111]. Dos tratados después, en el sexto, siendo "ya en este tiempo buen mozuelo", obtiene su primer trabajo lucrativo pregonando y vendiendo agua $^{7}$ al servicio de un capellán, y cuatro años más tarde, ya cerca de cumplir veinte años - según la cronología interna de la obra-, gracias a sus ahorros efectúa su primera gran compra. La noticia

${ }^{6}$ Recuérdese que el protagonista se presenta diciendo "a mí llaman Lázaro de Tormes", pero pocas líneas después, al mencionar su nacimiento en el río afirma "por la cual causa tomé el sobrenombre" [I, p. 12]. ¿Hay en estas dos afirmaciones una contradicción premeditada? ¿Está implícita la pasiva aceptación de un vulgar apodo o un acto de voluntad del marginado por darle al sobrenombre falsas sonoridades?

${ }^{7} \mathrm{El}$ trabajo de pregonero servía para que las clases populares, especialmente niños y jóvenes sin recursos ni oficio hábil, pudieran participar en el mundo del pequeño comercio, generalmente cerrado por las restricciones gremiales y económicas. La mayor actividad de los pregoneros consistía en trabajar para otros vendiendo mercancías a cambio de cierto porcentaje, en la compra-venta al menudeo, en especial de cosas usadas, y en anunciar los pregones públicos. Véanse al respecto, por ejemplo, las ordenanzas sevillanas de 1632, "De los pregoneros", citadas por Mary Elizabeth Perry, Crime and society in early modern Seville, The University Press of New England, Hanover, $\mathrm{NH}, 1980$, p. 42 y nota 18. 
detallada que nos da de ésta es reveladora de su importancia: se trata de ropa que, aunque vieja, le sirve para "me vestir muy honradamente". La elección del adverbio no nos parece casual, y menos aún si tenemos en cuenta la enumeración de las prendas: "un jubón de fustán viejo, y un sayo raído de manga trenzada y puerta, y una capa que había sido frisada y una espada de las viejas primeras de Cuéllar" [VI, p. 127]. Qué duda cabe que tanto esta vestimenta - que, con excepción de las calzas y el jubón, evoca la del propio escudero [III, pp. 81 y 92], tan preocupado por las apariencias y la honra -, como la adquisición de una espada - precisamente de Cuéllar, también como la del hidalgo-, adquieren un valor simbólico y social para un Lázaro hasta entonces harapiento y miserable. Al vestir "honradamente", el joven marginado adopta una apariencia que antes le había estado vedada y que da como resultado una imitación pobre de la del hidalgo. Poco importa que en la realidad de la época fuera raro que portara espada quien no era noble ni se dedicaba a las artes útiles ${ }^{8}$, y sólo ejercía una ocupación tan humilde como la de aguador. Lo importante en la realidad literaria del personaje es que la apropiación de esos símbolos aristocratizantes ${ }^{9}$ haga que su atuendo se asemeje al del escudero, su maestro en el arte del parecer, lo disfrace de "hombre de bien" y le preste respetabilidad.

Este afán por aparentar más de lo que se es, es el medio del cual se vale un Lázaro adulto y experimentado para ascender los escalones que le permitan "venir a alcanzar buena vida" [VI, p. 126]. Con el último tratado parece culminar el aprendizaje vital de Lázaro desde su infancia hasta la madurez, cuando el personaje alcanza un modesto oficio real como pregonero y entra a servir al arcipreste. Sin duda, a través de sus fortunas y adversidades, el humilde Lázaro aquilató el valor de enfrentarse solo a la vida sin naufragar en el camino", en contraste con "los que heredaron nobles estados" y tuvieron la Fortuna de su parte. Así, en el "Pró-

${ }^{8}$ Sólo los maestros de ciertos gremios y oficios llevaban espada para indicar sus privilegios; cf. Víctor SANz, "Trabajo y gremios en la España del Siglo de Oro", Boletín Histórico, Caracas, 43 (1977), p.38.

9 José Antonio Maravall habla de la "usurpación de signos estamentales", en "Un tópico sobre la estructura social: la imagen dicotómica de pobres y ricos", Monéda y crédito, 165 (1983), p. 56.

${ }^{10}$ Es bien sabido que la mortalidad infantil en la España del Lazarillo era muy alta, especialmente entre los niños de las clases marginadas. La sola supervivencia era considerada un triunfo sobre el destino. En esas circunstancias la niñez era efimera: para triunfar sobre el hambre, los niños pordioseros que jamás habían aprendido oficio útil, no sólo dependían de las oportunida- 
logo', que a la vez sirve de epílogo vital, el personaje-narrador afirma orgulloso haber llegado por sus propios esfuerzos a abrigo seguro: "cuánto más hicieron los que, siéndoles contraria, con fuerza y maña remando salieron a buen puerto" ["Prólogo", p. 11].

Al concluir la Vida, Lázaro demuestra haber aprendido bien todas las lecciones en el duro oficio de servir. Supo sobrevivir a las miserias en que lo tuvieron sus dos primeros amos y adquirió de ellos, a la par que su soledad esencial, el don de medrar, ya que "más da el duro que el desnudo" [I, p. 35]. Del escudero adoptó los consejos de "servir y contentar", de ser astuto y discreto. El Lázaro adulto, que en su vida matrimonial se desentiende de las habladurías sobre su mujer y que, indiferente a la posible afrenta a su honor, opta por la paz doméstica y la protección del arcipreste, tiene muy presente la lección del hidalgo de que los "hombres virtuosos" enfadan al poderoso y sabe bien que se gana muy poco con "la negra que llaman honra", por la que tanto padeció su tercer amo. Lazarillo ha aprendido desde muy niño, aun antes de comenzar su dura vida de servicios, que el mayor peligro que hay en la pobreza y el desamparo es estar solo frente a la ley -como lo estuvieron su padre y su padrastro- y opta, en cambio, por ser pregonero de crímenes y castigos ajenos. Él, al igual que su madre al quedar viuda y sola, ha determinado arrimarse a los buenos. A diferencia del padre, que al cabo de quince años de duro trabajo de molinero no pudo escapar de la miseria, el robo y el castigo, y del padrastro, atormentado también por hurtar por amor a los suyos, Lázaro - al margen de toda consideración ética o afectiva - acepta la vida del criado obsecuente, con tal de obtener seguridad y protección. Si desde un principio Lázaro aprendió a identificar bienestar con afecto, como en el caso del Zaide a quien quiso más a medida que "mejoraba el comer' [I, p. 17], al terminar de narrar su vida, el protagonista declara que ama a su mujer más que nada en el mundo, pues "me hace Dios con ella mil mercedes" [VII, p. 134]. Mientras pueda perpetuar su propia comodidad material, Lázaro acepta conforme un ménage à troïs que le permita obtener del arcipreste mercedes y provecho. Así, el fogueado personaje-narrador puede reflexionar al dirigirse al desconocido destinatario de su novelada epís-

des que les ofrecieran los adultos (que en el caso de Lazarillo eran mínimas), sino de la precoz capacidad individual de emular su habilidad, sabiduría e ingenio, desarrollada en el ir y venir de una vida ambulante y parasitaria. Cf: Mary Ellzabeth Perry, op. cit., cap. 9. 
tola cuánto valora "subir siendo bajos" y cómo condena a quienes se dejan "bajar, siendo altos" [I, p. 24].

Aunque resulte poco edificante, no es raro que el personaje concluya la narración de su vida cerrando los ojos a la inmoralidad que lo rodea. La realidad en la que se formó Lázaro desde sus ocho años ${ }^{11}$, es decir, desde que el padre fue apresado, estaba sustentada en una moral individual y colectiva cuyas normas fundamentales eran sobrevivir y, en lo posible, medrar, aun a costa de sumisión y engaño. Éstos fueron los principios que Lázaro asimiló tras largos años de penalidades en el lento y duro aprendizaje de criado. Poco debe sorprendernos - desde el punto de vista de la ficción- que la decisión final del personaje sea proteger aquello que logró después de tantos sacrificios: el bienestar material, la paz de su casa y la maestría en el oficio de servir.

Parecería que hemos llegado al final, pero no es así; en realidad, el desarrollo de Lázaro no concluye en el séptimo tratado, sino que el verdaderamente último capítulo de su vida es el "Prólogo'. Paradójicamente, el tiempo autobiográfico de estas primeras páginas no sólo es posterior al de las que cierran el libro, sino que, además, la maestría del personaje como servidor no culmina con el arcipreste sino en el "Prólogo", al servicio de "Vuestra Merced», el último y, a la vez, el primero y más poderoso de sus amos. Hasta ahora se nos había escapado que estas paradojas entrañan una compleja circularidad narrativa: la vida literaria del protagonista no concluye al terminar el libro sino cuando comienza la obra, es decir, cuando Lázaro obedece la orden que le ha dado "Vuestra Merced» de que "se le escriba y relate el caso", y recapitula su azarosa vida. Al aceptar hacerlo, el personaje-escritor reinicia en el "Prólogo" su oficio de servir nuevo amo. A partir de este momento, sólo nos queda volver a recorrer el círculo, enterarnos de nuevo del nacimiento de Lazarillo de Tormes y seguir otra vez sus fortunas y adversidades, desde sus primeros pasos, como mozo de ciego, hasta el final, como pregonero real y... Volvemos a comenzar.

Clara E. Lida

El Colegio de México

${ }^{11}$ Cristóbal Pérez de Herrera, Amparo de los legítimos pobres, Madrid, 1608 , recomienda que los varones pobres sean colocados para trabajar y aprender oficios y las niñas colocadas como sirvientas a los ocho años. Sin embargo, de acuerdo con la cronología interna de la obra, se puede calcular que cuando Lázaro comienza a servir al ciego tiene cerca de doce años. 